\title{
MODEL KEUNTUNGAN PEMASARAN BUNGA SEDAP MALAM DI SURABAYA
}

\author{
Koesriwulandari \\ koesriwulandari@uwks.ac.id \\ Dosen Program Studi Agribisnis \\ Fakultas Pertanian \\ Universitas Wijaya Kusuma Surabaya
}

\begin{abstract}
ABSTRAK
Salah satu peluang bisnis yang cukup menarik adalah budidaya tanaman hias. Salah satu bunga hias yang bisa dijadikan usaha adalah bunga sedap malam. Bunga sedap malam sangat diminati karena memeiliki bentuk yang cantik dan memeliki bau yang harum serta kesegaran yang mampu bertahan lama. Wanginya yang seharum melati dapat menenangkan hati orang di sekitarnya. Bunga sedap malam mempunyai sejumlah manfaat untuk kesehatan, mulai dari mengobati influenza sampai rematik.

Produksi bunga sedap malam pada tahun 2016 sebesar 69.365.952 tangkai, telah melampau target yang ditetapkan dalam RPJMD Kabupaten Pasuruan tahun 20132018 sebesar 31.570 .783 tangkai atau 19,72\%. Peningkatan produksi ini utamanya dipengaruhi oleh peningkatan luas panen dan produktivitas tanaman sedap malam. Potensi luas panen tanaman sedap malam yang ada di Kabupaten Pasuruan sampai dengan tahun 2016 mencapai $7.526 .399 \mathrm{~m}^{2}$. Oleh karena itu pemerintah provinsi Jawa Timur menetapkan bunga sedap malam sebagai maskot flora Jawa Timur dengan varietas roro anteng dan mengembangkan varietas dian arum dari Cianjur Jawa Barat

Tujuan Penelitian Untuk mengetahui faktor-faktor yang berpengaruh terhadap keuntungan pemasaran bunga sedap malam di tingkat pedagang di Surabaya. Model keuntungan dinyatakan dalam bentuk logaritma ganda sebagai berikut : $\mathrm{K}=\mathrm{b} 0+\mathrm{b} 1$ $\mathrm{B} 1+\mathrm{b} 2 \mathrm{~B} 2+\mathrm{b} 3 \mathrm{~B} 3+\mathrm{b} 4 \mathrm{~B} 4+\mathrm{b} 5 \mathrm{~B} 5+\mathrm{u}$.

Berdasarkan hasil analisis regresi linier berganda, maka model keuntungan pemasaran bunga sedap malam di Surabaya adalah sebagai berikut : KP $=-10678,705+$ 2,408 B1 - 11,532 B2 - 1..092 B3 + 33,688 B4 + e. Nilai koefisien determinasi sebesar $\left(\mathrm{R}^{2}=64,2 \%\right)$ berarti $64,2 \%$ keuntungan pemasaran bunga sedap malam di Surabaya dipengaruhi oleh variabel - variabel yang dimasukkan ke dalam model, yaitu transportasi, sewa, listrik dan retribusi, sedang sisanya $(35,8 \%)$ dipengaruhi oleh variabel lain yang tidak dimasukkan ke dalam model, misalnya tenaga kerja, sortasi, bongkar muat, penyimpanan. Secara simultan, berdasarkan F-statistik sebesar 4,478 dengan sigifikansi $0,025 \%$, diartikan bahwa secara simultan semua aktivitas pemasran yang dilakukan meliputi biaya transport, biaya sewa stand, biaya listrik dan biaya retribusi berpengaruh signifikan terhadap keuntungan pemasaran bunga sedap malam di Surabaya. Secara parsial aktivitas pemasarann yang berpengaruh significant terhadap keuntungan pemasaran adalah biaya transport dan biaya retribusi.
\end{abstract}

\section{Kata Kunci : Aktivitas Pemasaran Biaya Pemasaran, Keuntungan Pemasaran}

\section{PENDAHULUAN}

\section{Latar Belakang}

Bunga mempunyai nilai ekonomis yang relatif tinggi. Pengusahaan bunga di samping dapat meningkatkan pendapatan, juga banyak menyerap tenaga kerja, bahkan 
sebagai sumber devisa negara. Oleh sebab itu penanganan yang cukup dari berbagai pihak baik pemerintah maupun swasta sangatlah diperlukan.

Salah satu peluang bisnis yang cukup menarik adalah budidaya tanaman hias. Bunga hias potong merupakan salah satu komoditas yang banyak menyerap pasar, dimana bunga-bunga ini dapat dijadikan hiasan untuk acara-acara yang sifatnya formal misalnya untuk pernikahan, rapat kantor dan sarana media pendukung pesta sehingga acara tersebut bisa mendapat nilai tambah. Salah satu bunga hias yang bisa dijadikan usaha adalah bunga sedap malam.

Bunga sedap malam sangat diminati karena memeiliki bentuk yang cantik dan memeliki bau yang harum serta kesegaran yang mampu bertahan lama. Wanginya yang seharum melati dapat menenangkan hati orang di sekitarnya. Bunga sedap malam mempunyai sejumlah manfaat untuk kesehatan, mulai dari mengobati influenza sampai rematik.

Produksi bunga sedap malam pada tahun 2016 sebesar 69.365.952 tangkai, telah melampau target yang ditetapkan dalam RPJMD Kabupaten Pasuruan tahun 20132018 sebesar 31.570 .783 tangkai atau 19,72\%. Peningkatan produksi ini utamanya dipengaruhi oleh peningkatan luas panen dan produktivitas tanaman sedap malam. Potensi luas panen tanaman sedap malam yang ada di Kabupaten Pasuruan sampai dengan tahun 2016 mencapai $7.526 .399 \mathrm{~m}^{2}$. Oleh karena itu pemerintah provinsi Jawa Timur menetapkan bunga sedap malam sebagai maskot flora Jawa Timur dengan varietas roro anteng dan mengembangkan varietas dian arum dari Cianjur Jawa Barat (http://www.pasuruankab.go.id/potensi-121-sedap-malam-.html, 2017)

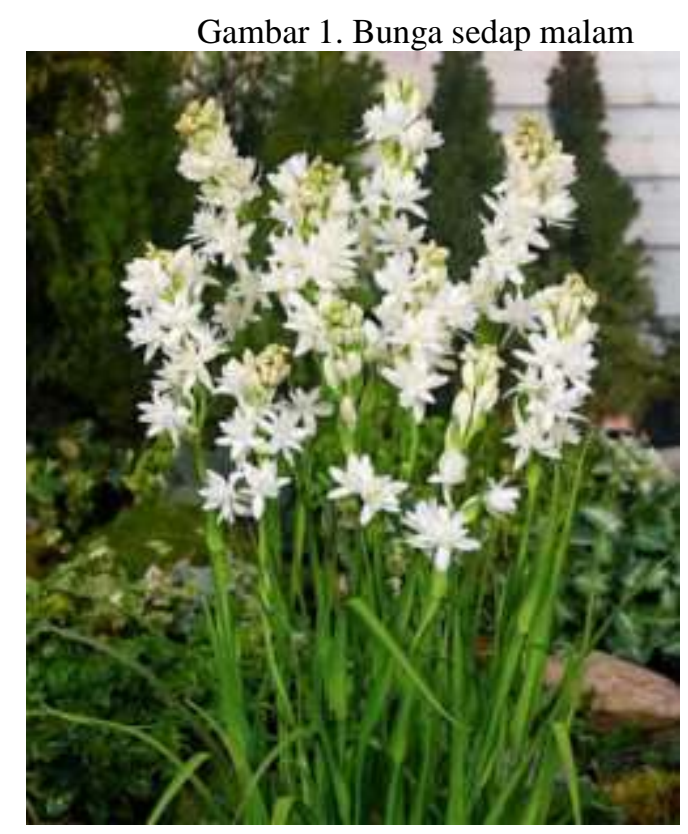

Bunga sedap malam dari Kabupaten Pasuruan di pasarkan di Pasuruan, Malang. Surabaya, Bali, Jakarta dengan harga berkisar antara 1.000/tangkai sampai dengan 1.500,-/tangkai di tingkat produsen (http://pasuruankab.go.id/potensi-57-sedap-malam.html, 2017).

Pada kegiatan pemasaran, peranan lembaga pemasaran cukup penting terutama dalam penentuan harga. Perbedaan harga ditingkat konsumen dan produsen (marjin pemasaran) tergantung dari besarnya keuntungan yang diambil oleh masing-masing 
lembaga sebagai balas jasa atas aktifitas yang dilakukan. Secara ideal sistem pemasaran harus dapat memberikan kepuasan kepada produsen, lembaga pemasaran dan konsumen melalui mekanisme yang efisien dalam mangintegrasikan penawaran dan permintaan

\section{Perumusan Masalah}

Berdasarkan latar belakang penelitian maka perumusan masalah dalam penelitian ini adalah : 1) Faktor apa saja yang berpengaruh terhadap keuntungan pemasaran bunga sedap malam di tingkat pedagang di Surabaya. 2) Berapa besarnya margin pemasaran bunga sedap malam di Surabaya.

\section{Tujuan Penelitian}

Untuk mengetahui faktor-faktor yang berpengaruh terhadap keuntungan pemasaran bunga sedap malam di tingkat pedagang di Surabaya

\section{Kegunaan Penelitian}

Sebagai bahan pertimbanagan bagi pedagang bunga sedap malam dalam meningkatkan keuntungan dan sebagai bahan pertimbangan dalam penelitian selanjutnya.

\section{TINJAUAN PUSTAKA \\ Hasil Penelitian Terdahulu}

Permintaan terhadap bunga potong sangat dipengaruhi o; eh selera konsumen. Umumnya konsumen bunga anggrek terbatas pada golongan menegh ke atas yang jumlahnya relatif sedikit. Maria (1991) dalam penelitian tentang perilaku konsumen anggrek di Kodya Surabaya, seseorang dalam membeli bunga potong pertama kali tertarik pada keindahan bunga (61\%), perlengkapan rangkaian bunga (10\%), menyusul service yang diberikan kepada konsumen (12\%) dan harga (17\%). Mugiono (1995), proses pengambilan keputusan dalam membeli bunga di pasar bunga Kodya Malang dipengaruhi oleh faktor ekstern (sosial ekonomi, pendidikan, umur, jenis kelamin, lingkungan, pekerjaan dan status perkawinan) dan faktor intern (hobby, kesenangan, koleksi, motivasi, kebanggaan). Faktor ekstern yang paling besar pengaruhnya adalah status perkawinansedangkan faktor intern adalah kesenangan.

Kiptiyah (1994) dalam penelitian tentang konsumsi dan pemasaran bunga potong di Kabupaten Malang, berdasarkan hasil analisis regresi model logaritma ganda, pendapatan dan total pengeluaran pangan berpengaruh positip terhadap konsumsi bunga potong non anggrek di Malang. Elastisitas pendapatan 1,44 berarti bunga merupakan barangnormal dan konsumsi rumah tangga terhadap bunga ini sangat peka terhadap perubahan harga. Total penge;luaran pangankomplemen dengan konsumsi bunga yang ditunjukkan oleh nilai elastisitas 1,62 sedangkan pendidikan mempunyai pengaruh negatif $(-0,3)$. Jumlah anggota RT, julah anggota RT yang bekerja, pekerjaan, agama, umur, luas halaman serta total pengeluaran non pangan secara signifikan tidak berpengaruh terhadap konsumsi bunga.

\section{Landasan Teori}

\section{Fungsi Pemasaran}

Kegiatan yang dilakukan oleh lembaga pemasaran dalam rangka menyampaikan komoditas/ jasa dari konsumen ke konsumen disebut fungsi pemasaran. Secara teoritis fungsi pemasaran dapat digolongkan menjadi 3 golongan, yaitu : (1) fungsi pertukatan (exchange function) yang meliputi penjualan, pembelian ; (2) fungsi fisik (physical function) yang meliputi fungsi pengangkutan, bongkar muat, pergudangan dan (30 fungsi pelancar (facilitating function) yang meliputi kegiatan yang menyangkut masalah 
standarisasi, dan grading, penanggungan resiko, pembiayaan dan kredit serta informasi pasar dan harga (Nashir, Haedar, 2017).

Bunga merupakan komoditas pertanian yang mempunyai sifat mudah rusak. Penanganan fungsi pemasaran yang kurang baik dapat mempengaruhi kekuatan pasar dari komoditas tersebut. Pada umumnya konsumen menghendaki bunga yang indah dan menarik dalam keadaan segar, tidak layu, dan dengan harga yang relatif murah. Untuk mendapatkan kondisi seperti itu, menurut Bahar (1995), perlu diperhatikan beberapa fungsi pemasarannya antara lain : (1) pemanenan sebaiknya dilakukan pada pagi hari sebelum matahari terbit, pukul 15.00 - 06.00 atau pada sore hari setelah matahari terbenam yaitu pukul 17.00. Hal ini untuk mengurangi laju kelayuan. Setelah pemanenan dilakukan, pangkal tangkai bunga (penduculus) dimasukkan ke dalam ember yang berisi air dan dibawa ke ruangan yang berpendingin, (2) pangkal penduculus dipotong miring, kemudin diberi kapas yang dibasahi air dan dibungkus dengan kantong plastik atau dimasukkan dalam tube yang berisi air, (3) kemudian dikemas, yang umumnya menggunakan karton dan (4) dikirim dengan alat transportasi yang umumnya digunakan seperti sepeda motor, mobil, kereta api, kapal laut dan sebagainya.

Kegiatan pemasaran membutuhkan biaya yang tidak sedikit. Setiap lembaga pemasaran mengambil keuntungan atas kegiatan yang dilakukan. Secara teori keuntungan adalah selisih antara penerimaan total (PrT) dengan biaya yang dikeluarkan (B) yang dirumuskan sebagai berikut :

$$
\mathrm{K}=\operatorname{PrT}-\mathrm{B}
$$

Dengan asumsi biaya yang dikeluarkan untuk mendapatkan keuntungan, maka keuntungan adalah fungsi dari biaya, yang dapat diturunkan sebagai berikut :

$$
\begin{array}{ll}
\mathrm{K} & =\mathrm{f}(\mathrm{Bi}) \\
\mathrm{K} & =\mathrm{f}(\mathrm{B} 1, \mathrm{~B} 2, \mathrm{~B} 3, \mathrm{~B} 4, \mathrm{~B} 5)
\end{array}
$$

dimana :

$$
\begin{array}{ll}
\mathrm{K} & =\text { Keuntungan Pemasaran } \\
\mathrm{B} 1 & =\text { Biaya Penyimpanan } \\
\mathrm{B} 2 & =\text { Biaya Pengemasan } \\
\mathrm{B} 3 & =\text { Biaya Transportasi } \\
\mathrm{B} 4 & =\text { Biaya Penanggungan Resiko } \\
\mathrm{B} 5 & =\text { Biaya Retribusi }
\end{array}
$$

dengan menggunakan fungsi logaritma ganda, maka fungsi keuntungan dirumuskan sebagai berikut :

$$
\begin{aligned}
K= & B o B 1^{\beta 1} B 2^{\beta 2} B 3^{\beta 3} B 4^{\beta 4} B 5^{\beta 5} \\
\log K= & \log B o+\beta 1 \log B 1+\beta 2 \log B 2+\beta 3 \log B 3+\beta 4 \log \\
& B 4+\beta 5 \log B 5+u
\end{aligned}
$$

dimana :

$$
\begin{array}{ll}
\mathrm{B} 0 & =\text { konstanta } \\
\mathrm{Bi} & =\text { share dari Bi terhadap } \mathrm{K}
\end{array}
$$

Berdasarkan analisis ini maka dapat diketahui share dari masing-masing fungsi pemasaran, sehingga dapat diketahui fungsi pemasaran yang seharusnya diperhatikan karena pengaruhnya terhadap keuntungan pemasaran.

\section{Hubungan Harga di Tingkat Produsen dan Konsumen}

\section{a. Marjin Pemasaran}

Marjin pemasaran (Marketing Margin) merupakan selisish antara harga suatu produk yang dibayar oleh konsumen dengan harga yang diterima oleh produsen. 
Menurut Masyrofie, 1991 marjin pemasaran dapat didefinisikan : (a) perberdaan harga yang dibayarkan oleh konsumen dengan harga yang diterima oelh produsen, atau (b) biaya dan jasa-jasa pemasaran yang dibutuhkan sebagai akibat permintaan dan penawaran dari jasa-jasa pemasaran. Biaya dan jasa pemasaran tersebut dimaksudkan meliputi biaya pemasaran yang dikeluarkan oleh lembaga pemasaran yang terlibat dalam melakukan fungsi pemasaran dan keuntungan yang diperoleh sebagai imbal jasa melakukan fungsi pemasaran tersebut. Jadi komponen marjin pemasaran itu terdiri dari (a) biaya pemasaran dan (b) keuntungan pemasaran.

Secara grafis marjin pemasaran merupakan jarak vertikal antara harga di tungkat konsumen dengan harga di tingkat produsen (gambar 2).

Gambar 2. Marjin Pemasaran

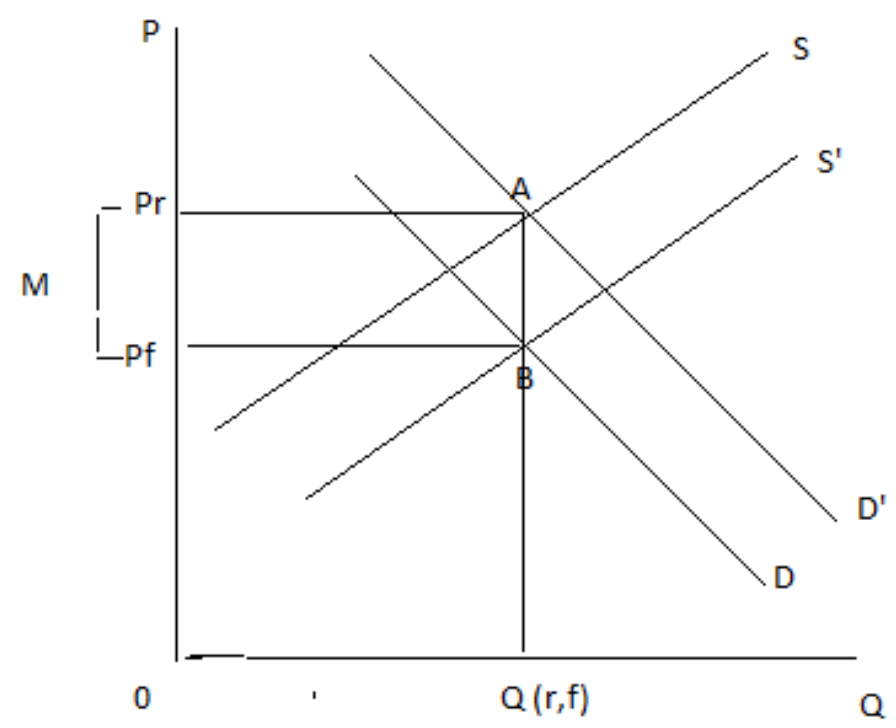

Keterangan :

$\mathrm{Sf}=$ Kurva Penawaran Produsen

Df $=$ Kurva Permintaan produsen

$\mathrm{Sr}=$ Kurva Penawaran Pengecer/ Konsumen

$\mathrm{Dr}=$ Kurva Permintaan Pengecer/ Konsumen

Harga di tingkat pengecer adalah merupakan perpotongan kurva permintaan primer (PrimaryDemand Curve) dan kurva penawaran turunan (Derived Supply Curve), sedangkan harga di tingkat produsen merupakan perpotongan kurva permintaan turunan (Derived Demand Curve) dan kurva penawaran primer (Primart Supply Curve) (Tomek Robinson, 1981).

Secara matematis marjin pemasaran dapat dirumuskan sebagai berikut :

$\mathrm{MP}=\mathrm{Pr}-\mathrm{Pf}$

dimana :

MP = Marjin Pemasaran

Pr = Harga di tingkat Konsumen

Pf $=$ Harga di tingkat Produsen

atau

$\mathrm{MP}=\mathrm{KP}+\mathrm{BP}$ 
dimana :

$\mathrm{KP}=$ Keuntungan Pemasaran

$\mathrm{BP}=$ Biaya Pemasaran

share keuntungan lembaga pemasaran ke-i adalah :

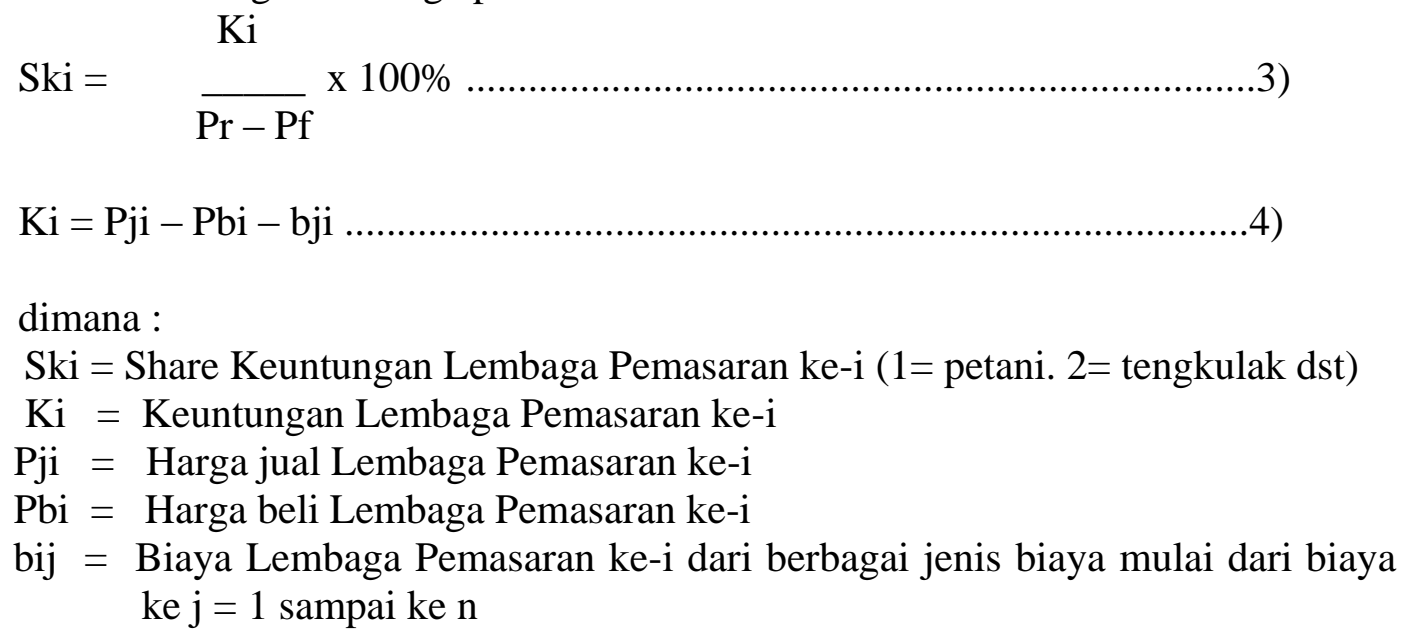

share biaya lembaga pemasaran ke-i dan jenis biaya pemasaran ke-j adalah : bi

$$
\text { Sbi }=\frac{\mathrm{P}}{\operatorname{Pr}-\mathrm{Pf}}
$$

dimana :

Sbi $=$ Share biaya pada Lembaga Pemasaran ke $-\mathrm{i}$

bi = Biaya Pemasaran pada Lembaga Pemasaran ke -i

Pr $=$ Harga di tingkat pengecer

Pf = Harga di tingkat petani

Berdasarkan analisis marjin pemasaran tersebut maka akan dapat dilihat :

1) Bagaimana perbandingan share keuntungan dari masing-masing lembaga pemasaran yang terlibat dalam proses pemasaran, apakah merata ataru justeru petani dirugikan. 2) Bagaimana perbandingan share keuntungan dengan biaya pemasarannya apakah cukup logis atau tidak, dari berbagai lembag pemasaran yang terlibat dalam proses pemasaran

\section{Kerangka Berfikir}

Pemasaran merupakan proses penyampaian komoditas dari produsen sampai ke konsumen malalui saluran pemsaran tertentu. Aktivitas yang dilakukan oleh lembaga pemasaran dalam rangka penyampaian bunga sedap malam kepada konsumen pada prinsipnya meliputi : (1) fungsi pertukatan (exchange function), yaitu suatu tindakan untuk memperlancar pemindahan hak milik dan jasa meliputi fungsi penjualan dan pembelian, (2) fungsi fisik (physical function), yaitu semua tindakan terhadap komoditas sehingga memperoleh kegunaan waktu dan tempat, khususnya trnsportasi dan distribusi dan (3) fungsi pelancar (facilitating function), yaitu semua tinadakan yang menunjang kelancaran pelaksanaan fungsi fisik, antara lain sortasi, grading, penanggungan resiko, penyuautan alat. Sebagaimana dikeltahui bahwa bunga mempunyai sifat yang mudah rusak dan tidak tahan lama sehingga komoditas ini 
membutuhkan perlakuan yang memadai dalam pemasarannya agar sampai ke konsumen dengan kualitas tinggi. Fungsi pemasaran yang dilakukan oleh lembaga pemasaran yang berkonsekuensi pada biaya dimaksudkan untuk menambah nilai guna dari komodiatas yang diapasarkan. Lembaga pemasaran mengambil keuntungan sebagai balas jasa dari fungsi pemasaran yang dilakukan. Secara rinci keuntungan pemasaran merupakan selisih antara penerimaan total (PrT) dengan biaya total(Bi).

$$
\mathrm{K}=\text { PrT }-\mathrm{Bi}
$$

Dengan asumsi bahwa biaya pemasaran yang dikeluarkan diharapkan adanya peningkatan keuntungan, maka secara fungsional, fungsi keuntungan dirumuskan sebagai berikut:

$$
\mathrm{K}=\mathrm{f}(\mathrm{B} 1, \mathrm{~B} 2, \mathrm{~B} 3, \ldots \mathrm{Bn})
$$

Dimana $\mathrm{K}=$ keuntungan pemasaran

$\mathrm{Bi}=$ biaya pemsaran masing-masing lembaga pemasaran

Besarnya keuntungan yang diambil lembaga pemasaran akan mempengaruhi besarnya marjin. Hal ini dalam pengertian jika biaya persatuan produk itu sama sedangkan keuntungan persatuan yang diambil oleh lembaga pemasaran itu berbeda, maka besarnya marjin pemasaran juga berbeda.

$$
\mathrm{MP}=\mathrm{Pr}-\mathrm{Pf}
$$

Atau

$$
\mathrm{MP}=\mathrm{KP}+\mathrm{BP}
$$

Dimana $: \mathrm{MP}=$ marjin pemasaran

$\operatorname{Pr}=$ harga di tingkat konsumen

Pf = harga di tingkat pedagang

Atau

$$
\begin{aligned}
& \mathrm{KP}=\text { keuntungan pemasaran } \\
& \mathrm{BP}=\text { biaya pemasaran }
\end{aligned}
$$

Menurut Mubyarto (1989), pemasaran komoditas pertanian dinyatakan efisien jika mampu menyampaikan hasil-hasil pertanian kepada konsumen dengan biaya semurah-murahnya serta mampu mengadakan pembagian yang adil dari keseluruhan harga yang dibayarkan konsumen akhir kepada semua pihak yang ikut serta dalam kegiatan produksi dan pemasaran komoditas tersebut. Oleh sebab itu dari analisis marjin pemasaran dilihat juga bagaimana rasio antara keuntungan dan biaya dari masingmasing lembaga pemasaran yang terlibat dalam memperoleh keuntungan.

\section{Hipotesis}

Hipotesis dalam penelitian ini adalah:

Diduga keuntungan pemasaran bunga sedap malam dipengaruhi oleh biaya transport, biaya pengemasan, penanggungan resiko.

\section{METODE PENELITIAN}

\section{Metode Penentuan Lokasi Penelitian}

Daerah penelitian ditentukan secara sengaja (purposive) yaitu kota Surabaya yang merupakan daerah potensial untuk konsumen bunga potong sedap malam. Konsumen bunga sedang malam meliputi konsumen rumah tangga dan konsumen non rumah tangga diantaranya perkantoran, rumah makan serta hotel yang banyak dijumpai di kota Surabaya. Lokasi penelitian di Surabaya tepatnya di jalan Kedungdoro Surabaya dengan pertimbangan merupakan sentra penjualan Pedagang Kaku Lima (PKL) bunga sedap malam. 


\section{Metode Penentuan Responden}

Responden dalam penelitian ini ada pedagang kaki lima bunga sedap malam di jalan Kedungdoro Surabaya. Metode penentuan responden dengan menggunakan Teknik Sampling Sensus, yaitu sejumlah 15 pedagang kaki lima bunga sedap malam, seluruhnya dijadikan sebagai responden.

\section{Metode Pengumpulan Data}

Data yang diperlukan dalam penelitian ini adalah data primer dan data sekunder.

Data primer diambil dari responden secara langsung, yaitu lembaga pemasaran/ pedagang kaki lima bunga sedap malam dengan menggunakan daftar pertanyaan (questionary) yang telah dipersiapkan sebelumnya. Sedangkan data sekunder diambil dari instansi yang terkait untuk menunjang penelitian ini.

\section{Metode Analisis Data}

\section{1) Analisis Marjin Pemasaran}

Marjin pemasaran dapat digunakan untuk menganalisis efisiensi pemasaran secara menyeluruh (Saefuddin, 1983). Melalui analis marjin dapat diketahui :

a. Perbandingan share keuntungan dari masing-masing lembaga pemasaran

b. Perbandingan share keuntungan dengan biaya pemasaran Marjin pemasaran secara matematis dirumuskan :

$$
\begin{aligned}
& \mathrm{MP}=\mathrm{Pr}-\mathrm{Pf}=\mathrm{KP}+\mathrm{BP} \\
& \text { dimana }: \mathrm{MP}=\text { Marjin Pemasaran } \\
& \mathrm{Pr}=\text { Harga di Tingkat Konsumen } \\
& \mathrm{Pf}=\text { Harga di Tingkat Produsen } \\
& \mathrm{KP}=\text { Keuntungan Pemasaran } \\
& \mathrm{BP}=\text { Biaya Pemasaran }
\end{aligned}
$$

\section{2) Analisis Keuntungan Pemasaran}

Dengan asumsi bahwa biaya pemasaran yang dikeluarkan dengan harapan adanya peningkatan keuntungan, maka fungsi keuntungan dirumuskan sebagai berikut :

$$
\begin{aligned}
& \mathrm{KP}=\mathrm{f}(\mathrm{B} 1, \mathrm{~B} 2, \mathrm{~B} 3, \mathrm{~B} 4, \mathrm{~B} 5) \\
& \text { dimana }: \\
& \mathrm{KP}=\text { Keuntungan lembaga pemasaran (Rp/ikat/hari) } \\
& \mathrm{B} 1=\text { Biaya Perawan (Rp/ikat) } \\
& \mathrm{B} 2=\text { Biaya Transportasi (Rp/ikat) } \\
& \mathrm{B} 3=\text { Biaya Retribusi (Rp/ikat) } \\
& \mathrm{B} 4=\text { Biaya Resiko (Rp/ikat) } \\
& \mathrm{B} 5=\text { Biaya Penjualan (Rp/ikat) }
\end{aligned}
$$

Untuk melihat faktor share dari Bi serta pertimbangan semua variabel dinyatakan dalam satuan rupiah (expenditure) maka fungsi keuntungan dinyatakan dalam bentuk logaritma ganda sebagai berikut :

$$
\begin{aligned}
& K=b o B 1 b 1 B 2 b 2 B 3 b 3 \text { B4 b4 B5 b5 } \\
& K=b 0+b 1 B 1+b 2 B 2+b 3 B 3+b 4 B 4+b 5 B 5+u
\end{aligned}
$$

$$
\begin{aligned}
\text { dimana : } & \text { bi } \\
\mathrm{u} & =\text { Koefisien regresi, } \mathrm{i}=1,2 \ldots 5 \\
& \text { Kesalahan }
\end{aligned}
$$

\section{Pengujian Hipotesis}

Sebelum dilakukan pengujian koefisien regresi, terlebuh dahulu dilakukan pengujian model persamaan regresi (uji-F), yang diformulasikan sebagai berikut : 


$$
\mathrm{F}-\text { hitung }=\frac{\text { KT Regresi }}{\text { KT Acak }}
$$

Selanjutnya dilakukan uji statistik :

Ho $:$ bi $=0$, semua nilai bi sama dengan nol

$\mathrm{Ha} \quad$ : bi $\neq 0$, paling sedikit terdapat satu nilai bi tidak sama dengan nol

Kriteria uji statistik :

F-hit $\leq$ F-tabel $(0,05)(\mathrm{k}, \mathrm{n}-\mathrm{k}-1)$, maka Ho diterima yang berarti semua biaya pemasaran tidak berpengaruh terhadap keuntungan pemasaran

F-hit >F-tabel $(0,05)(\mathrm{k}, \mathrm{n}-\mathrm{k}-1)$, maka Ho ditolak yang berarti semua biaya pemasaran berpengaruh terhadap keuntungan pemasaran

Untuk mengetahui pengaruh variabel bebas terhadap variabel tidak bebas secara parsial digunakan uji t-statistik :

Ho $\quad$ : bi $=0$, semua nilai bi sama dengan nol

Ha $\quad$ : bi $\neq 0$, paling sedikit terdapat satu nilai bi tidak sama dengan nol

Besarnya t-hitung dirumuskan sebagai berikut :

bi

$$
\mathrm{T}-\text { hitung }=\frac{}{\mathrm{Se}(\mathrm{bi})}
$$

Dimana :

$$
\begin{array}{ll}
\mathrm{Se}(\mathrm{bi}) & =\text { simpangan baku dari bi } \\
\mathrm{Bi} & =\text { koefisien regresi }
\end{array}
$$

Kriteri uji :

$\mathrm{t}$-hit $\leq \mathrm{t}$-tabel $(0,05)(\mathrm{k}, \mathrm{n}-\mathrm{k}-1)$, maka Ho diterima yang berarti biaya pemasaran secara parsial tidak berpengaruh terhadap keuntungan pemasaran bunga sedap malam

t-hit > t-tabel $(0,05)(k, n-k-1)$, maka Ho ditolak yang berarti biaya pemasaran secara parsial berpengaruh terhadap keuntungan pemasaran bunga sedap malam

\section{Batasan dan Pengukuran Variabel}

1. Pemasaran bunga sedap malam dalam penelitian ini dibatasi pada lembaga pemasaran/pedagang kaki lika di Kota Surabaya

2. Lembaga pemasaran adalah individu/ lembaga yang menyelenggarakan proses pemindahan bunga sedap malam sampai konsumen akhir dengan melakukan fungsi pemasaran

3. Konsumen adalah pembeli terakhir dari sedap malam. Dalam penelitian ini dibatasi pada konsumen yang membeli bunga sedap malam melalui lembaga pemasaran/ pedagang kaki lima atau konsumen yang membeli di pasar bunga, dengan pertimbangan tidak mengetahui aktivitas secara keseluruhan dari pelaku-pelaku pasar dalam pemasaran bunga sedap malam.

4. Fungsi pemasaran adalah aktivitas-aktivitas yang dilakukan oleh lembaga pemasaran untuk menambah guna/ nilai dari bunga sedap malam yang dipasarkan

5. Biaya pemasaran (BP) adalah biaya yang dikeluarkan oleh lembaga pemasaran dalam melakukan fungsi pemasaran yang dinyatakan dalam Rp/ikat/hari

6. Harga jual $(\mathrm{Pj})$ adalah rata-rata harga penjualan pedagang kaki lima bunga sedap malam yang dinyatakan dalam Rp/ikat 


$$
P j=\frac{Q j i \times P j i}{Q j i}
$$

dimana: $\quad$ Qji $=$ kuantum penjualan lembaga pemasaran ke $\mathrm{i}$

$\mathrm{Pji}=$ harga jual lembaga pemasaran ke $\mathrm{i}$

7. Harga Beli $(\mathrm{Pb})$ adalah rata-rata harga yang dibayarkan oleh konsumen akhir, dinyatakan dalam Rp/ikat

$$
\mathrm{Pb}=\frac{\text { Qbi x Pbi }}{\text { Qbi }}
$$

dimana: $\quad$ Qbi $=$ kuantum penjualan lembaga pemasaran ke $\mathrm{i}$

$\mathrm{Pbi}$ = harga jual lembaga pemasaran ke $\mathrm{i}$

8. Penerimaan (Tr) adalah selisih harga jual dan harga beli dikalikan jumlah kuantum yang dijual

$$
\operatorname{Tr}=(\mathrm{Pji}-\mathrm{Pbi}) \quad \mathrm{x} \mathrm{Qji}
$$

9. Keuntungan Pemasaran (KP) adalah selisih antara penerimaan dengan biaya pemasaran, dinyatakan dalam Rp/ikat/hari. Keuntungan Pemasaran merupakan bagianyang diterima oleh pedagang sebagai imbalan atas aktivitas yang dilakukannya.

$$
\mathrm{Kpi}=\mathrm{Tri}-\mathrm{Bi}
$$

dimana : $\mathrm{KPi}=$ keuntungan lembaga pemasaran ke $\mathrm{i}$

$$
\text { Tri = penerimaan lembaga pemasaran ke } \mathrm{i}
$$

10. Marjin pemasaran adalah selisih harga yang dibayarkan oleh konsumen dengan harga yang dierima oleh pedagang atau jumlah antara biaya pemasaran dengan keuntungan pemasaran.

\section{HASIL DAN PEMBAHASAN}

Pemasaran adalah proses penyampaian barang dari produsen kepada konsumen. Pedagang perantara yang terlibat dalam pemasaran tersebut, melakukan beberapa aktivitas pemasaran yang dimaksudkan untuk meningkatkan nilai guna dari komoditas yang dipasarkan. Aktivitas pemasaran ini berpengaruh langsung terhadap biaya pemasaran, dengan asumsi bahwa pedangang melakukan aktivitas yang berkonsekuensi pada biaya pemasaran, dimaksudkan untuk meningkatkan keuntungan pemasaran.

\begin{tabular}{|c|c|c|c|c|c|c|}
\hline \multirow{2}{*}{\multicolumn{2}{|c|}{ Model }} & \multicolumn{2}{|c|}{$\begin{array}{c}\text { Unstandardized } \\
\text { Coefficients }\end{array}$} & \multirow{2}{*}{$\begin{array}{c}\text { Standardized } \\
\text { Coefficients } \\
\text { Beta }\end{array}$} & \multirow[b]{2}{*}{$t$} & \multirow[b]{2}{*}{ Sig. } \\
\hline & & B & Std. Error & & & \\
\hline \multirow[t]{5}{*}{1} & (Constant) & $-100678,705$ & 58527,286 & & $-1,720$ &, 116 \\
\hline & Transport & 2,408 & 1,013 & 1,080 & 2,377 & ,039 \\
\hline & Sewa & $-11,532$ & 7,914 &,- 558 & $-1,457$ & , 176 \\
\hline & Listrik & $-1,092$ & 2,326 &,- 096 &,- 470 & 649 \\
\hline & Retribusi & 33,688 & 8,947 & 1,142 & 3,765 & ,004 \\
\hline
\end{tabular}
Keuntungan pemasaran diduga dipengaruhioleh beberapa biaya diantaranya biaya transportasi, biata sewa stand, biaya listrik serta biara retribusi, dengan hasil analisis sebagai berikut :

Tabel. 1. Hasil Analisis Regresi Faktor yang Berpengaruh Secara Parsial terhadap

Keuntungan Pemasaran Bunga Sedap Malam

Coefficients $^{\mathrm{a}}$

a. Dependent Variable: Keuntungan 
Berdasarkan hasil analisis regresi linier berganda, maka model keuntungan pemasaran bunga sedap malam adalah sebagai berikut :

$\mathrm{KP}=-10678,705+2,408 \mathrm{~B} 1-11,532 \mathrm{~B} 2-1 . .092 \mathrm{~B} 3+33,688 \mathrm{~B} 4+\mathrm{e}$

Nilai Konstanta (a)

Nilai konstanta menunjukkan besarnya keuntungan jika aktivitas yang dilakukan oleh pedagang dalam pemesaran bunga sedap dianggap konstan. Tanpa adanya biaya yang dikeluarkan dalam proses pemasaran dalam arti tanpa adanya kegiatan pemasaran maka pedagang akan mengalami kerugian sebesar Rp. 1.0678

Koefisien Determinasi $\left(\mathbf{R}^{2}\right)$

Koefisien determinasi menunjukkan menunjukkan ketepatan dari model keuntungan pemasaran bunga sedap malam di Surabaya. Berdasarkan hasil analisis Koefisien Determinasi sebesar $\left(\mathrm{R}^{2}=64,2 \%\right)$ berarti $64,2 \%$ keuntungan pemasaran bunga sedap malam di Surabaya dipengaruhi oleh variabel - variabel yang dimasukkan ke dalam model, yaitu transportasi, sewa, listrik dan retribusi, sedang sisanya (35, 8\%) dipengaruhi oleh variabel lain yang tidak dimasukkan ke dalam model, misalnya tenaga kerja, sortasi, bongkar muat, penyimpanan.

\section{Pengaruh Variabel Secara Simultan}

Aktivitas yang dilakukan oleh pedagang pengecer dalam pemasaran bunga sedap malam di Surabaya meliputi :

1. Transport

2. Sewa Stand

3. Listrik

4. Retribusi

Berdasarkan hasil analisis, nilai F-statistik sebesar 4,478 dengan sigifikansi 0,025\%, diartikan bahwa secara simultan semua aktivitas pemasran yang dilakukan meliputi biaya transport, biaaya sewa stand, biaya listrik dan biaya retribusi berpengaruh signifikan terhadap keuntungan pemasaran bunga sedap malam di Surabaya (Tabel. 18)

Tabel. 2. Hasil Analisis Regresi Faktor yang Berpengaruh Secara Simultas terhadap Keuntungan Pemasaran Bunga Sedap Malam di Surabaya Tahunn 2017

\begin{tabular}{|ll|c|r|r|r|r|}
\hline \multicolumn{1}{|l|}{ Model } & Sum of & Mean & & \\
& & Squares & df & Square & F & Sig. \\
\hline 1 & Regression & $1,914 \mathrm{E} 10$ & 4 & $4,784 \mathrm{E} 9$ & 4,478 &, $025^{\mathrm{a}}$ \\
& Residual & $1,068 \mathrm{E} 10$ & 10 & $1,068 \mathrm{E} 9$ & & \\
& Total & $2,982 \mathrm{E} 10$ & 14 & & & \\
\hline
\end{tabular}

a. Predictors: (Constant), Retribusi, Listrik, Sewa, Transport

b. Dependent Variable: Keuntungan

\section{Faktor-Faktor yang Berpengaruh Terhadap Keuntungan Pemasaran Bunga Sedap} Malam di Surabaya

1. Biaya Transport

Transportasi adalah pemindahan komoditas dalam hal ini bunga sedap malam dari produsen atau pedagang sebelumnya kepada konsumen akhir. Peranan aktivitas ini sangat penting, untuk meningkatkan nilai guna tempat.

Berdasarkan hasil analisis uji t (Tabel 1), nilai t -statistika $(2,377)$ dengan significant sebesar 0,039 berarti secara parsial biaya transportasi berpengaruh 
significant terhadap keuntungan pemasaran bunga sedap malam di Surabaya. Nilai koefisien regresi sebesar 2,408 yang berarti jika biaya transportasi dinaikkan sebesar Rp 1,- maka keuntungan pemasaran akan meningkat sebesar Rp. 2,408

2. Biaya Sewa Stand

Stand adalah tempat pedagang berjualan. Besarnya sewa yang ditanggung oleh pedagang tergantung dari besarnya/ luasnya tempat berjualan. Semakin besar stand semakin banyak jumlah bbarang yang diperjualbelikan.

Berdasarkan hasil analisis, nilai $\mathrm{t}$ - statistika $(-1,457)$ dengan nilai significant sebesar 0,176 berarti secara parsial biaya sewa tidak berpengaruh significant terhadap keuntungan pemasaran bunga sedap malam di Surabaya. Nilai koefisien regresi sebesar - 11,532 yang berarti jika biaya transportasi dinaikkan sebesar Rp 1,- maka keuntungan pemasaran akan menurun sebesar Rp. 11,532. Tidak significant pengaruh biaya sewa terhadap keuntungan karena, pedagang lebih memilih menjual bunga di sepanjang bahu jalan pasar, meskipun tersedia stand di lantai satu pasar bunga Jl Kedongdoro.

3. Biaya Listrik

Listrik digunakan untuk penerangan selama kegiatan berjualan, serta untuk perawatan/penyiraman bunga.

Berdasarkan hasil analisis uji $t$, nilai $t$-statistika ( - 0,470) denngan nnilai significat sebesar 0,649 berarti secara parsial biaya listrik tidak berpengaruh significant terhadap keuntungan pemasaran bunga sedap malam di Surabaya. Nilai koefisien regresi sebesar -1,092 yang berarti jika biaya listrik dinaikkan sebesar Rp 1,- maka keuntungan pemasaran akan menurun sebesar Rp. 1,092

4. Biaya Retribusi

Menurut UU no. 28 tahun 2009 Retribusi adalah pungutan daerah sebagai pembayaran atas jasa atau pemberian ijin tertentu yang khusus disediakan dan/ atau diberikan oleh Pemerintah Daerah untuk kepentingan pribadi atau golongan. Retribusi dibayarkan setiap hari oleh pedagang untuk kepentingan penjualan bunga di pasar bunga Kedongdoro.

Berdasarkan hasil analisis uji t, nilai t -statistika $(3,765)$ denngan nilai significant sebesar 0,004 berarti secara parsial biaya retribusi berpengaruh significant terhadap keuntungan pemasaran bunga sedap malam di Surabaya. Nilai koefisien regresi sebesar 33,688 yang berarti jika biaya retribusi dinaikkan sebesar Rp 1,- maka keuntungan pemasaran akan meningkat sebesar Rp. 33,688.

\section{KESIMPULAN}

Berdasarkan hasil dan pembahasan diatas dapat disimpulkan sebagai berikut :

1. Untuk biaya transportasi nilai koefisien regresi sebesar 2,408 yang berarti jika biaya transportasi dinaikkan sebesar Rp 1,- maka keuntungan pemasaran akan meningkat sebesar Rp. 2,408.

2. Untuk biaya sewa stand nilai koefisien regresi sebesar - 11,532 yang berarti jika biaya transportasi dinaikkan sebesar Rp 1,- maka keuntungan pemasaran akan menurun sebesar Rp. 11,532. Tidak significant pengaruh biaya sewa terhadap keuntungan karena, pedagang lebih memilih menjual bunga di sepanjang bahu jalan pasar, meskipun tersedia stand di lantai satu pasar bunga Jl Kedongdoro.

3. Untuk biaya listrik nilai koefisien regresi sebesar -1,092 yang berarti jika biaya listrik dinaikkan sebesar $\mathrm{Rp}$ 1,- maka keuntungan pemasaran akan menurun sebesar Rp. 1,092 
4. Untuk biaya retribusi nilai koefisien regresi sebesar 33,688 yang berarti jika biaya retribusi dinaikkan sebesar Rp 1,- maka keuntungan pemasaran akan meningkat sebesar Rp. 33,688.

5. Secara simultan, berdasarkan F-statistik sebesar 4,478 dengan sigifikansi 0,025 \%, diartikan bahwa secara simultan semua aktivitas pemasran yang dilakukan meliputi biaya transport, biaya sewa stand, biaya listrik dan biaya retribusi berpengaruh signifikan terhadap keuntungan pemasaran bunga sedap malam di Surabaya. Secara parsial aktivitas pemasarann yang berpengaruh significant terhadap keuntungan pemasaran adalah biaya transport dan biaya retribusi.

\section{DAFTAR PUSTAKA.}

Bahar, FA dan Widyastoeti,D. 1995. Perkembangan Teknologi Anggrek. Pusat Penelitian dan Pengembangan Hortikultura. Departemen Pertanian. Jakarta.

Gujarati. 1988. Basic Econometrics. Mc. Graw Hill Company. New York.

Kartasapoetro, G dan Kartasapoetro, AG. 1986. Marketing Produk Pertanian dan Industri yang Diterapkan di Indonesia. Bina Aksara. Jakarta.

Kiptiyah, S. 1994. Konsumsi dan Pemasaran Bunga di Jawa Timur. Universitas Brawijaya. Malang.

Maria. 1991. Analisis Perilaku Konsumnen Bunga Anggrek di Surabaya. Skripsi Jurusan Sosial Ekonomi Fakultas Pertanian Universitas Wijaya Kusuma Surabaya. Surabaya.

Masyrofie. 1991. Pemasaran Hasil-hasil Pertanian. Jurusan Sosial Ekonomi Fakultas Pertanian Universitas Brawijaya. Malang.

Mubyarto. 1989. Pengantar Ekonomi Pertanian. LP3ES. Jakarta.

Mugiono. 1995. Analisis Faktor-faktor yang Mempengaruhi Perilaku Pembeli Bunga di Pasar Bunga Kodya Malang. Fakultas Ekonomi. Universitas Brawijaya. Malang.

Nashir, H. 2017. Pemasaran Pertanian. Cetakan kedua No. ISBN. 979-3921-12-8 UMM Press. Universitas Muhammadiyah Malang

Tomek, CW dan Robinson, LK. 1981. Agricultural Product Price. Cornel University Press. London.

Widyawan, R. 1994. Bunga Potong : Tinjauan Literature. Pusat Dokumentasi dan Informasi Ilmiah. Lembaga Pusat Ilmu Pengetahuan Indonesia. Jakarta.

http://pasuruankab.go.id/potensi-57-sedap-malam-.html, diakses pada tanggal 21 April 2018. 